\title{
Sobre a tese "ser que pode ser compreendido é linguagem": hermenêutica como teoria filosófica
}

\author{
On the claim "being that can be understood is language": \\ hermeneutics as philosophical theory
}

\begin{abstract}
Viviane Magalhães Pereira
vivianefilosofia@yahoo.com.br

(Pontifícia Universidade Católica do Rio Grande do Sul, Rio Grande do Sul,

Brasil)
\end{abstract}

\begin{abstract}
Resumo: 0 presente artigo tem 0 propósito de refletir sobre a tese de HansGeorg Gadamer (1900-2002): "ser que pode ser compreendido é linguagem". Essencialmente, ela representa uma crítica às concepções tradicionais de linguagem e, ao mesmo tempo, uma mudança de objetivos da própria hermenêutica. Há várias interpretações sobre essa afirmação, mas alguns dos seus elementos não foram explorados. A relevância desse tipo de pesquisa é compreender em parte a teoria hermenêutica de Gadamer e a sua contribuição para a Filosofia.
\end{abstract}

Palavras-chave: Gadamer; linguagem; hermenêutica.

\begin{abstract}
In this paper we attempt to think about the Hans-Georg Gadamer's claim: "being that can be understood is language". Substantially, this is a criticism to the traditional conceptions of language and at the same time a change in the purposes of Hermeneutics. There are a lot of interpretations about this claim, but some aspects of it were not explored. The relevance of such study is to understand Gadamer's Hermeneutics und its contribution to Philosophy.
\end{abstract}

Keywords: Gadamer; language; hermeneutics.

\section{Introdução}

"Não há método que ensine a perguntar, a ver o que se deve questionar"1. Com essa afirmação, o filósofo Hans-Georg Gadamer quis dizer que o caminho para a verdade de muitas experiências, como aquela da arte ou da elaboração das próprias perguntas, não é aquele do método e do objeto. Foi em busca de outros caminhos que Gadamer trouxe para a Filosofia a sua obra Verdade e método. Para tanto, ele defendeu, em primeiro lugar, a seguinte tese: se quisermos elaborar as questões que mais nos afetam como mortais, portadores de culturas e representantes de tradições,

1 GADAMER, H-G. Wahrheit und Methode: Grundzüge einer philosophischen Hermeneutik. 6. ed. Gesammelte Werke, Bd. 1. Tübingen: Mohr Siebeck, 1990, p.371. 
a ideia de verdade desenvolvida com a adoção do método das ciências empíricas do século XVII, e refinada pelos lógicos, analistas da linguagem e teóricos da informação, é insuficiente. Por um lado, ela desempenha aí uma função secundária e, por outro, ela elimina ou reduz aquelas questões, quando busca atestar sua legitimidade.

Há um diálogo que sempre ocorreu na história da humanidade. 0 que esse diálogo traz é o que pré-ordena todo nosso comportamento. Trata-se de ações recíprocas, na leitura de um texto, em uma conversa, ao se desempenhar uma tarefa conjunta no cotidiano, etc., nas quais há o confronto com o outro. Além dessa exigência de compreensão do que nos é diverso, todos nós também nos deparamos em tais acontecimentos com o processo de compreensão de si mesmo e, assim, de reflexão de nossas possibilidades de ação no mundo.

De forma ainda mais fundamental, para Gadamer todas as atividades humanas possuem a seguinte dimensão hermenêutica: elas estão fundadas nos acordos e convenções que se realizam na linguagem, que, por sua vez, está em constante processo de mudança. Isso significa que nenhuma proposta de solução de um problema tem uma qualidade infinita. É importante que possamos vê-la como uma perspectiva que se estabeleceu ao invés de outras.

Se a teoria é, sob o ponto de vista da ciência moderna, um saber preciso, que visa ser posto em prática, nós teríamos então que dizer o que significa aqui "teoria" e quais os limites deste conceito. Na Modernidade, o termo "teoria" é determinado em oposição à aplicação prática. Por um lado, há o domínio e posterior esclarecimento de uma multiplicidade de coisas e, por outro, o uso desse conhecimento em uma situação concreta, como se ele fosse a orientação mais adequada. Assim, a teoria é compreendida como um modelo anônimo de verdades, e não como uma atitude própria do ser humano.

Gadamer quis mostrar com Verdade e método, dentre outras coisas, que esse modelo de verdade não é e nem deve ser o único. Quando se trata das nossas capacidades técnicas, ele desempenha bem a sua função, isto é, trazer relativa segurança e conforto ante algumas necessidades que já existiam e outras que foram criadas. Entretanto, quando estão em questão nossa história e linguagem, nosso relacionamento com a arte e com a religião, nossa consciência da morte, nosso autoconhecimento, nossas escolhas e ações responsáveis, nossa vivência política, dentre outras experiências que nos dizem respeito como seres humanos finitos que somos, esse modelo de verdade fracassa.

Neste artigo pretendemos expor como a hermenêutica de Gadamer trata desse problema. Para tanto, tentaremos mostrar em que sentido o seu projeto filosófico, por um lado, afasta-se daqueles que incorporaram a ideia de método das ciências da natureza e, por outro, traz uma abordagem diferenciada para a questão da compreensão, em relação a outras propostas da tradição hermenêutica na Filosofia. 
Isso nos conduz até a tese de Gadamer sobre ser e linguagem e, por fim, a sua tentativa de, mediante a defesa de uma universalidade do fenômeno da compreensão, converter a hermenêutica em uma teoria filosófica.

\section{O primado do conceito de finitude: os ensinamentos da tradição hermenêutica}

O problema especial de acesso à verdade pertence à história da humanidade, desde que os seres humanos buscaram entender a mensagem dos deuses. É tanto que

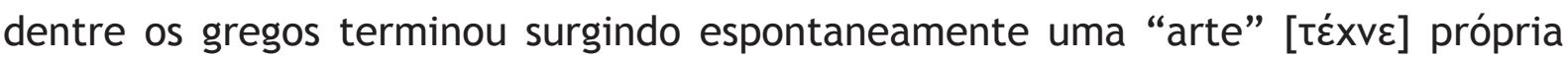

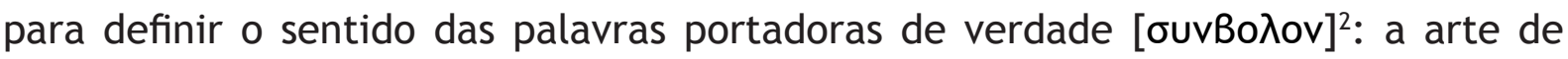

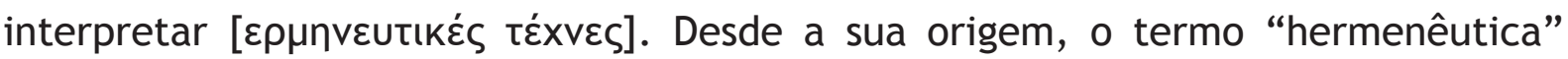
representou a nossa dificuldade de determinar precisamente o sentido de uma mensagem. Com o passar do tempo, ela foi cada vez mais se aperfeiçoando como um cânone de regras, para a exegese adequada de obras que apresentavam uma dificuldade de compreensão, como textos sagrados, jurídicos e literários. Todavia, enquanto "técnica", a hermenêutica nunca concluiu plenamente a tarefa de transformar textos obscuros, em textos acessíveis, apenas com a leitura do texto pelo texto.

Faltava, em primeiro lugar, a compreensão do contexto histórico ao qual eles pertenciam e, assim, do conjunto de expectativas e vivências em meio ao qual eles foram criados. Foi uma consequência da Aufklärung acreditar que até esses conteúdos da história, os quais se haviam tornado estranhos para nós, também nos poderiam ser acessíveis por meio de nossas atividades racionais, isto é, de uma reflexão teórica. No entanto, segundo Gadamer, foi somente Schleiermacher quem radicalizou essa problemática. Este defendeu que, para a "arte" de compreender adequadamente as obras, mais importante do que captar a unidade entre o conteúdo do texto e a tradição, seria aceitar que o esforço da compreensão só surge onde há a permanente possibilidade de um mal-entendido ${ }^{3}$. Em outras palavras, o problema da interpretação estaria na própria natureza do compreender, pois dela faz parte a possibilidade do mal-entendido, especialmente quando se trata de interpretar algo como a obra de arte e o discurso fixado por escrito, os quais provêm de um outro indivíduo, de outra forma de compreensão.

Portanto, para Schleiermacher, a tarefa de compreender um texto se deve converter também em um esforço para compreender outra individualidade. Essa é a tarefa maior, pois, no fim, também implica autocompreensão. Como alguém pode entender o que the era estranho, se permanece com as mesmas convicções?

2 Cf. ARISTÓTELES. “Periérmeneias”. In: Organon. Tradução de Pinharanda Gomes. Lisboa: Guimarães Editores, 1985, pp.123-128.

3 Cf. GADAMER, H-G. Wahrheit und Methode, pp.182-183. 
Buscar compreender o que está presente no texto seria deixar vir à tona, portanto, uma verdade que diz respeito tanto ao autor como a nós mesmos. Seguindo esse propósito, Schleiermacher isolou o procedimento do compreender, buscou para ele uma "metodologia" própria ${ }^{4}$ e criou uma ciência capaz de descrever as suas condições, isto é, uma hermenêutica geral.

Isso significou afirmar, em primeiro lugar, que há uma unidade entre todas as formas de interpretação $0^{5}$, oriunda da própria estrutura da compreensão; em segundo lugar, que, além do método gramatical (comparativo), o uso de um método psicológico (divinatório) é imprescindível ${ }^{6}$; e, em terceiro lugar, que a hermenêutica é mais do que um conjunto de regras, pois ela precisa ser buscada ${ }^{7}$ na palavra escrita ou falada, em outras individualidades e, especialmente, em nós mesmos.

A maior contribuição de Schleiermacher talvez tenha sido alertar, ao fim, para a impossibilidade de revelar totalmente o "mistério" que é a individualidade humana. Apesar de realizarmos idas e vindas, da palavra ao conceito e do conceito à palavra, da autocompreensão à compreensão do outro e vice-versa, como nos ensina o círculo hermenêutico da parte e do todo, o que conquistamos é "apenas" uma aproximação da verdade do outro. Depois desse movimento circular, estamos em condições de compreender melhor ${ }^{8}$, até melhor, por exemplo, do que o próprio autor de um texto se compreendeu', mas não em definitivo.

Ainda assim, Dilthey considera problemática essa pretensão de compreender a intenção inconsciente de um autor, pois ainda fica em aberto como uma individualidade pode "transformar em conhecimento objetivo com valor universal o dado sensível que é, para ela, uma manifestação vital de uma outra individualidade" ${ }^{10}$. Esse problema epistemológico surge quando se isola o intérprete da sua própria compreensão da vida, pois, por mais que toda individualidade seja uma manifestação da vida do todo e traga em si mesma um pouco de cada um, ela mesma nunca se encontra isolada do "fluxo da vida".

Segundo Gadamer, foi principalmente Dilthey quem se conscientizou dos limites do psicologismo, decorrente da abstração metodológica de Schleiermacher,

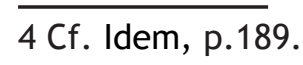

5 "A hermenêutica enquanto arte de compreensão ainda não existe universalmente, mas somente várias hermenêuticas especiais” (SCHLEIERMACHER, F. D. E. Hermenêutica e crítica. Tradução de Aloísio Ruedell. Rev. Paulo R. Schneider. Ijuí: Editora Unijuí, 2005, p.91).

6 Qualquer compreensão consiste "em dois momentos: compreender o discurso enquanto extraído da linguagem e compreendê-lo enquanto fato naquele que pensa" (Idem, p.95).

7 Cf. Idem, p.113.

8 Cf. Idem, p.116.

9 Cf. SCHLEIERMACHER, F. D. E. Hermenêutica: arte e técnica da interpretação. 5. ed. Tradução de Celso Reni Braida. Bragança Paulista: Editora Universitária São Francisco, 2006, p.69; SCHLEIERMACHER, F. D. E. Hermenêutica e crítica, p.115.

10 DILTHEY, W. "Origens da hermenêutica". In: Textos de hermenêutica. Tradução de Alberto Reis. Lisboa: Rés, 1984, p.167. 
e tentou pensar a hermenêutica como uma base epistemológica adequada para as ciências do espírito. Ela portaria justamente um conjunto de procedimentos capaz de considerar a totalidade dos "nexos" da história11. Compreender certos textos ou mesmo outra individualidade, no fundo é compreender, em algum nível, o valor que é inerente à história. Em outras palavras, tudo aquilo que está ligado aos seres humanos, enquanto seres históricos, exige de nós o esforço da compreensão. Esse é o universo do que foi denominado "ciências do espírito", diferente daquele das ciências que investigam a natureza.

Assim, Dilthey aplicou o princípio hermenêutico do todo e da parte à própria realidade histórica. Hermenêutica deixou de ser aqui uma "arte da interpretação", para auxiliar na fundamentação da filosofia da vida ${ }^{12}$, cujo processo não obedece ao princípio de causalidade tão caro às ciências da natureza, mas ao próprio movimento da história. A vida humana se expressa de modos variados, que não respeitam regras lógicas, embora ela possua unidades de significado duradouras, que se transmitem ao longo do tempo por meio de suas interpretações. É por isso que podemos afirmar que a vida ligada à história possui uma estrutura hermenêutica ${ }^{13}$. A cada vez que se interpreta o seu significado, ocorre nela uma espécie de acréscimo de si mesma, diferente de outras formas da natureza, que apenas se repetem. As formas históricas e as suas respectivas ciências dependem, portanto, das experiências daquele ser que é histórico, o ser humano, e do seu modo de compreendê-las. Enquanto houver vida, haverá história e significados em toda a sua variedade a serem novamente compreendidos ${ }^{14}$, do mesmo modo que, enquanto houver história, haverá compreensão e autocompreensão.

Se Dilthey, por um lado, reconheceu com isso a limitação de toda exegese, uma vez que aí nem a história nem a compreensão chegariam a um fim ${ }^{15}$, por outro lado, ele utilizou categorias como as do sujeito transcendental, para elaborar uma crítica da razão histórica. Em outros termos, ele tentou transformar a experiência histórica em ciência, para articular uma nova fundamentação para as ciências do espírito. Segundo Gadamer, em clara analogia com o questionamento kantiano, Dilthey fez uso de categorias do mundo histórico, como vivência, expressão e compreensão, com o objetivo de extrair daí um conteúdo objetivo e dar à razão histórica uma justificação como aquela da razão pura ${ }^{16}$.

11 Cf. GADAMER, H-G. Wahrheit und Methode, pp.201-202.

12 "A vida é o fato fundamental que deve constituir o ponto de partida da Filosofia; é o que conhecemos desde o interior, é aquilo para além do qual se não pode penetrar" (DILTHEY, W. "Origens da hermenêutica", p.184).

13 Cf. GADAMER, H-G. Wahrheit und Methode, p.230.

14 DILTHEY, W. "Origens da hermenêutica”, p.178.

15 Cf. Idem, pp.163; 170.

16 Cf. GADAMER, H-G. Wahrheit und Methode, pp.223-225. 
É precisamente aí que surge o seguinte problema: se as expressões da vida, também como manifestação da história, estão em constante mudança, como extrair daí um conteúdo objetivo sem deturpar a sua verdade? Como tal conteúdo, o nexo histórico, pode fazer jus à experiência histórica, se ele não é mais vivido por indivíduo algum, se ele atesta apenas uma regularidade da vida humana? Essa tensão de objetivos entre encontrar uma nova forma de pensar as ciências do espírito e ultrapassar com a consciência da história toda limitação de nossas experiências, na busca de uma objetividade para a história, fez com que as reflexões epistemológicas de Dilthey fossem um tanto contraditórias, visto que elas não estão de acordo com o seu ponto de partida, que é a ideia de uma filosofia da vida.

Somente uma retomada do caminho aberto por Dilthey, atendendo a objetivos distintos daqueles da consciência histórica, tornou possível um posterior desenvolvimento adequado da ideia de finitude, tão central para a hermenêutica de Gadamer. Husserl deu continuidade a essa tarefa de pensar um outro conceito de verdade com a sua fenomenologia, ao tentar superar o problema epistemológico da compreensão. A ideia era criticar mais radicalmente o objetivismo da filosofia tradicional, que esquecera do modo subjetivo de as coisas se darem, e investigar a manifestação do objeto no sujeito transcendental, mostrando que este já aponta intencionalmente de certo modo para o objeto, como isto ou aquilo. A diferença dessa teoria da intencionalidade da consciência para a tese kantiana do sujeito transcendental é que para aquela não há consciência vazia: toda consciência já é consciência de algo e todo comportamento é sempre comportamento para com alguma coisa ${ }^{17}$.

Desse modo, segundo Gadamer, Husserl assumiu a tarefa filosófica de pensar a subjetividade transcendental como fenômeno, isto é, examiná-la na variedade dos seus modos de doação ${ }^{18}$, para somente então retomar o caminho de volta às "coisas mesmas". A partir disso, temas desenvolvidos pela hermenêutica, como o da verdade ante a variabilidade dos modos de compreensão, poderiam ser melhor elucidados.

Para Husserl, no entanto, a dificuldade de enfrentar esse problema é aquela com a qual a teoria do conhecimento já se vem deparando há muito tempo: a compreensão da consciência subjetiva do tempo como algo que é diferente do tempo objetivo. Enquanto este representa a duração de uma coisa, naquela o tempo aparece de certo modo. Não somente o tempo, mas a própria intuição do espaço se consuma como percepção e fantasia, ou seja, as coisas espaciais aparecem para a consciência de tal e tal maneira. Portanto, tempo e espaço precisam ser suspendidos como fato e reduzidos à consciência de suas vivências, o que não pode ser encontrado na ordem empírica objetiva. Espaço objetivo, tempo objetivo e, com eles, mundo objetivo,

17 Cf. Idem, p.229.

18 Cf. Idem, p.249. 
já são eles mesmos transcendências. Os dados temporais que chegam à consciência já estão circunscritos por certas pretensões de avaliar, ordenar e distinguir de certo modo e representam, como fenômeno, uma mudança em relação ao objeto, o qual, ao contrário é algo duradouro ${ }^{19}$.

Diante disso, o propósito de Husserl passa a ser analisar fenomenologicamente essa mudança, expondo as verdades a priori que pertencem aos diversos momentos constitutivos em que a consciência visa isto ou aquilo. A cada um desses tempos, em que algo acontece, há um horizonte anterior e outro posterior que se ligam às suas respectivas vivências do anterior e do posterior, e isso não é nenhuma realidade da qual dispomos objetivamente ${ }^{20}$. Por essa razão, pensar como se constituem essas unidades de vivência do tempo não seria uma perda, mas sim o primeiro passo para formular apropriadamente a pergunta pela essência da verdade.

Contudo, segundo Gadamer, a autorreflexão husserliana que indagou sobre aquelas verdades a priori não foi suficientemente radical. Embora o problema da constituição dos objetos na e pela consciência fosse relevante, era a vida, e os seus nexos, que representava o problema fenomenológico propriamente dito. Só há algo como uma fusão do horizonte do anterior com o do posterior, porque há um horizonte de mundo. Em seus escritos posteriores, Husserl falou de uma intencionalidade anônima, como um horizonte de mundo, que englobaria tudo. Há um mundo no qual nos introduzimos pelo simples fato de vivermos e que não pode ser objeto de nenhuma ciência, uma vez que representa o solo prévio de toda experiência. Ele é o mundo da vida [Lebenswelt] e é por causa dele que é possível algo como a transição de intencionalidades particulares para uma contínua conservação de sentidos ${ }^{21}$.

De acordo com Gadamer, Husserl terminou mostrando que a unidade do nexo vivencial é anterior e essencialmente necessária frente à individualidade das vivências ${ }^{22}$. Embora isso represente um paradoxo dentro da sua proposta inicial de tornar a Filosofia uma ciência rigorosa, por meio da fenomenologia transcendental, ele contribuiu para dar prosseguimento a outro tipo de abordagem filosófica, que tem como ponto de partida a vida em suas determinações concreto-históricas. Além disso, foi da investigação da intencionalidade elaborada pela fenomenologia de Husserl que Heidegger iniciou suas reflexões ${ }^{23}$ e destas que o conceito de finitude trouxe algumas respostas para o problema hermenêutico da compreensão.

Heidegger pretendia ultrapassar o campo temático da consciência transcendental e das teorias da subjetividade como um todo, ao introduzir a história

19 Cf. HUSSERL, E. Lições para uma fenomenologia da consciência interna do tempo. Tradução de Pedro M. S. Alves. Lisboa: Imprensa Nacional, 1994, pp.37-41.

20 Cf. Idem, pp.42-43.

21 Cf. GADAMER, H-G. Wahrheit und Methode, p.250.

22 Cf. Idem, p.254.

23 Cf. Idem, p.247. 
como condição mais profunda de possibilidade da própria subjetividade. Isso significou inverter a questão da fundamentação na Filosofia e pôr novamente no seu centro a pergunta pelo ser, mas agora com a seguinte alegação: o ser mesmo fora esquecido pela tradição filosófica, pois para se pensar a questão do ser devemos em primeiro lugar abandonar a ideia de que um ser finito possa dizer o que ele é ${ }^{24}$. Ademais, é porque somos finitos que determinamos tudo o que pode ser pensado, tudo o que pode ser questionado, dentro de um período de tempo. Parece então que a questão do ser deveria permanecer como uma pergunta orientadora, para que nos déssemos conta dos limites de nossas reflexões. Ela não era para ser respondida.

Se não somos capazes de compreender o ser em si mesmo, o que nos é permitido compreender? 0 que significa lidarmos com a nossa finitude a ponto de ainda termos condições de manter como meta o alcance da verdade? Ante esses problemas filosóficos, Heidegger desenvolveu o que ele chamou de "hermenêutica da facticidade". Hermenêutica aqui significa a interpretação da condição do ser humano, em primeiro lugar, de ser determinado temporalmente pelos acontecimentos histórico-culturais dos quais ele faz parte e, em segundo lugar, de ao mesmo tempo compreendê-los. Desse modo, há uma transformação dos questionamentos transcendental e epistemológico na reivindicação de uma nova postura ontológica: Quais as implicações de pensar o ser no tempo? Antes de tudo, transferir a preocupação filosófica de categorizar a razão, o sujeito, a consciência, para outra de buscar na própria vida os indícios de que a atitude de compreender depende muito mais de um âmbito de sentidos prévio, do que de uma análise da nossa forma subjetiva de julgar.

Mais importante que a subjetividade é o fato de desde o nascimento estarmos inseridos em um mundo permeado de significados, de nos relacionarmos com outros, de termos a experiência de presenciar a morte de outros, de algo como a história nos influenciar constantemente, de sermos no horizonte do tempo, de projetarmos possibilidades futuras de nós mesmos. Isso tudo não pode pertencer a uma área do conhecimento, mas pode ser levado em consideração quando se trata de apontar para a definição do que consideramos ser verdadeiro. Essa era de um modo geral também da fenomenologia de Husserl, isto é, de tentar reencontrar a possibilidade de pensarmos em algo como a "verdade" nos dados originários da experiência. Mas, segundo Gadamer, as "descrições fenomenológicas de Heidegger são perfeitamente corretas quando enfatizam, no seio dos pretensos 'dados imediatos', a estrutura de antecipação que é constitutiva de toda compreensão”25. Consequentemente, para Heidegger, mesmo a fenomenologia precisa de uma hermenêutica.

Fenomenologia hermenêutica quer dizer que todos os nossos conhecimentos

24 Cf. HEIDEGGER, M. “Que é Metafísica?”. In: Conferências e escritos filosóficos. 2. ed. Tradução de Ernildo Stein. São Paulo: Abril Cultural, 1983.

25 GADAMER, H-G. O problema da consciência histórica. Tradução de César Duque Estrada. Rio de Janeiro: Editora Getúlio Vargas, 1998, p.64. 
de fenômenos são pré-determinados pelas nossas expectativas de sentido. Nunca teremos a chance de saber o que teríamos conhecido se as nossas expectativas tivessem sido diferentes. E o que nos chama a atenção é não podermos ser tão seletivos quanto às nossas expectativas, pois, por um lado, não há compreensão fora da história e, por outro, não temos um ponto privilegiado de observação fora da história a partir do qual pudéssemos diferenciar talvez algumas expectativas de outras. 0 nosso interesse por compreender não se origina de um critério geral, que se supõe neutro, imparcial, e visa ser aplicado a um caso particular ${ }^{26}$. Ele não surge de um a priori puro kantiano, mas emerge na medida em que já somos dentro de um mundo de significados.

Essa tese heideggeriana de uma estrutura prévia da compreensão modificou o papel da hermenêutica. Esta deixou de ser empregada como um método próprio das ciências do espírito, para contribuir para a análise do modo de ser do ser humano, inclusive de ser capaz de fazer ciência. Nas palavras de Heidegger:

Fenomenologia do Dasein é hermenêutica no sentido originário da palavra, em que se designa o ofício de interpretar. Na medida, porém, em que se desvendam o sentido do ser e as estruturas fundamentais do Dasein em geral, abre-se o horizonte para qualquer investigação ontológica dos entes não dotados do caráter do Dasein. (...) Nessa hermenêutica é então enraizado, na medida em que ela elabora ontologicamente a historicidade do Dasein como condição ôntica de possibilidade da história dos fatos históricos, o que somente se pode denominar de um modo derivado "hermenêutica": a metodologia das ciências históricas do espírito27.

Portanto, para Heidegger, há também duas dimensões em que podemos falar de algo como "verdadeiro", uma dimensão ôntica e outra ontológica. Quando se trata do ôntico, a verdade do objeto possui certa estabilidade, pois não pode ser alterada por quaisquer influências, desde que os critérios de validade sob os quais ela repousa sejam mantidos. Por outro lado, quando é o caso do ontológico e, com isso, da essência da verdade, nós seres humanos, enquanto aqueles capazes de perguntar pelo sentido do ser, talvez estejamos em proximidade da verdade, mas nunca em sua posse $^{28}$.

Essa diferença ontológica a partir da qual Heidegger desenvolveu sua ontologia fundamental trouxe uma ênfase para a seguinte tese: somos finitos. Nossas concepções nunca são absolutas, mas relativas ao contexto no qual estamos inseridos e à situação na qual nos encontramos com outros. Em outros termos, a compreensão

26 Cf. Idem, p.57.

27 HEIDEGGER, M. Sein und Zeit. Tübingen: Max Niemeyer Verlag, 1967, pp.37-38.

28 Cf. HEIDEGGER, M. "Sobre a essência da verdade". In: Conferências e escritos filosóficos; HEIDEGGER, M. "Aletheia (Heráclito, fragmento 16)". In: Ensaios e conferências. 3. ed. Tradução de Marcia Sá Cavalcante Schuback. Petrópolis: Vozes, 2006. 
se forma historicamente e temporalmente e, portanto, nem mesmo a história está sob nosso controle. Esta possui um sentido próprio. Apesar dessas declarações, a hermenêutica mesma não se destacou como principal preocupação de Heidegger, na medida em que falha ante o ser, o qual não pode ser compreendido. Aliás, como afirmou Gadamer, “Heidegger só se interessou pela problemática da hermenêutica histórica com a finalidade ontológica de desenvolver, a partir dela, a estrutura prévia da compreensão"29.

Gadamer tinha pretensões diversas das de Heidegger com relação à hermenêutica. Com ela, Gadamer queria defender, em primeiro lugar, a universalidade do problema da interpretação, isto é, que toda compreensão já é interpretação, na medida em que sofre certos efeitos da história, ao invés de outros. Para defender essa ideia, ele fez uso de um conceito chamado "história continuamente influente" [Wirkungsgeschichte]. Ele significa, em linhas gerais, que não importa o quanto saibamos ou sejamos experientes, a história continua nos influenciando em algum nível por meio da tradição da qual fazemos parte.

Em segundo lugar, a preocupação de Gadamer não era com a questão do ser. Se há ser que não pode ser compreendido, esse não é um tema para a compreensão. Por outro lado, o ser que pode ser compreendido precisa ser buscado, pela simples razão de que, ao contrário, sentidos, valores, conteúdos de um modo geral que dizem respeito aos seres humanos, seriam perdidos. Daí a sua tão famosa frase: "Ser que pode ser compreendido é linguagem"30. 0 ser, que pode ser compreendido, por fazer parte da história humana, está na forma de linguagem. Esse ser não nos é plenamente acessível por causa de nossa condição finita, de sofrermos apenas certos efeitos da história e ainda de somente nos tornarmos conscientes de alguns dentre estes efeitos, mas não porque ele não possa ser compreendido. Nenhum ser humano é capaz de compreender todo o conteúdo da história presente na tradição na forma de linguagem. A própria tradição possui um privilégio e uma autoridade sobre nós, visto que os seus efeitos perduram seja insconscientemente ou conscientemente e, neste caso, ao reproduzi-los ou negá-los.

A ideia de finitude aqui lembra a de Heidegger, mas desta difere em algo fundamental: não é o caso que o Dasein tenha a condição especial de perguntar pelo ser, embora não possa obter resposta que não converta o ser em ente, mas que o ser humano sempre mantém algo em comum com a tradição ${ }^{31}$, que the dá a chance de, de algum modo, compreender o ser. Isso significa que na própria linguagem falada, por exemplo, manifesta-se a oportunidade de compreendermos o que as coisas são, porque nela é mantido um vínculo com algo que humanamente vem se

29 GADAMER, H-G. Wahrheit und Methode, p.270.

30 "Sein, das verstanden werden kann, ist Sprache" (Idem, p.478).

31 Cf. GADAMER, H-G. O problema da consciência histórica, p.59. 
desenvolvendo ao longo da história. Mesmo os conhecimentos científicos só podem ser considerados integralmente como uma experiência humana quando incorporam a ela o saber pessoal do indivíduo que faz ciência ${ }^{32}$. Esse saber pessoal nada mais é do que aquilo que é aprendido em conjunto, na família e na sociedade, como a língua materna, bem como o conhecimento que o indivíduo a partir daí tem de si mesmo. o que chamamos de verdade, por exemplo, depende do nosso modo ocidental de compreender, que encontrou sua maior expressão no pensamento grego. Por que não falarmos, então, de "verdade ocidental"?

Esses questionamentos surgem quando levamos a hermenêutica de Gadamer às últimas consequências. Isso mostra como ele transforma a hermenêutica em uma teoria universal da compreensão e, por que não dizer, em um modo de se fazer Filosofia. Da hermenêutica surgida na tradição romântica até a hermenêutica filosófica de Gadamer vemos um distanciamento que não nos permite falar de uma única hermenêutica, mas de várias hermenêuticas, como, por exemplo, uma hermenêutica clássica, uma hermenêutica histórica, uma fenomenologia hermenêutica e uma hermenêutica filosófica. Contudo, é somente com Gadamer que ela ganha o estatuto de teoria filosófica e, assim, pode ser aplicada a todo o âmbito de reflexão da Filosofia.

\section{Hermenêutica como teoria filosófica: ser e linguagem}

A tese gadameriana da universalidade da hermenêutica possui dois argumentos centrais: a condicionalidade histórica, representada pelo conceito de "história continuamente influente", e a condicionalidade em relação aos outros de toda compreensão, representada por meio do conceito de "aplicação" [Anwendung] $]^{33}$. Nisso reside o sentido mais próprio de a tomarmos por uma filosofia da finitude. Nossa compreensão é limitada, por um lado, pela linguagem que adquirimos no contato com a tradição histórica e, por outro, pelo nosso diálogo com o outro. Desse modo, aquela tese de Gadamer está ligada principalmente às seguintes teses: a linguagem tem um caráter ontológico e a compreensão possui uma dimensão prática.

Aqui discorreremos apenas sobre o tema da linguagem e sobre a sua relevância para o projeto filosófico de Gadamer. O seu interesse pela história notoriamente não tinha a ver com uma disputa de métodos com outras ciências, mas também não dizia respeito à primazia da pergunta pelo ser. Se a história e, com ela, a linguagem possuem um caráter ontológico, isso significa antes de tudo que elas precedem nossas experiências, mesmo aquelas no âmbito da ciência, enquanto não podem ser posse de um sujeito, mas fundadoras e ao mesmo tempo resultantes de nossa humanidade.

32 Cf. GADAMER, H-G. "Klassische und philosophische Hermeneutik" [1968]. In: Wahrheit und Methode: Ergänzungen; Register. 2. ed. Gesammelte Werke, Bd. 2. Tübingen: Mohr Siebeck, 1993, p.137.

33 Cf. GADAMER, H-G. Die Lektion des Jahrhunderts: ein Interview von Riccardo Dottori. Münster: Lit, 2002, p.21. 
Como indivíduos, temos história e linguagem, mas isso só é possível na medida em que há, em um nível não completamente determinado por nós, algo como uma história e uma linguagem comuns. Enquanto Hegel queria converter toda substancialidade em subjetividade e transformar toda subjetividade em objeto ${ }^{34}$, Gadamer fez o movimento inverso. Ele tentou mostrar que em toda subjetividade há uma substancialidade (história, linguagem, tradição) que a determina, isto é, diante da qual somos finitos.

Portanto, há na filosofia hermenêutica uma “historicização" da razão. Nesse sentido, é retirado o poder da razão quer de ser capaz de trazer uma resposta definitiva, quer de ter mesmo que em algum nível resposta para tudo. Por um lado, busca-se responder a pergunta pela "utilidade" da Filosofia ante as pretensões da ciência de controlar todo âmbito da vida humana e, por outro, mostra-se como o ser somente pode ser compreendido dentro de um processo inacabado, no qual nós não temos a última palavra. Nossa vida não é preenchida somente com descrições de objetos, ela é algo em movimento. E só faz sentido falarmos assim, porque sempre há coisas novas a serem descobertas, não importa o quanto já saibamos.

Em outros termos, há a cada vez "ser" que pode ser compreendido e todo ele nos é acessível em forma de linguagem. Entretanto, não temos temporalmente e historicamente condições de apanhá-lo, seja por meio de resquícios do passado, de fatos do presente, de nossas próprias experiências ou do autoconhecimento. Que a linguagem tenha um caráter ontológico quer dizer: não podemos pensá-la sem “fazermos uso" dela. Que não haja pensamento sem linguagem, faz com que ela seja, segundo Gadamer, uma das coisas mais obscuras com a qual a reflexão humana já se deparou ${ }^{35}$. Ela é o verdadeiro vestígio de nossa finitude e já sempre nos ultrapassou. "A consciência de um indivíduo não é o parâmetro de medida com o qual o seu ser pode ser medido" ${ }^{36}$. Cada objetivação que dela se faz falha em algo fundamental: independente do quanto ela se tenha lançado "diante dos nossos olhos", ela ainda continua atuando.

Com essa tese de que "ser é linguagem", a própria ontologia torna-se hermenêutica. Somente compreendemos porque somos em meio à linguagem, tudo o que compreendemos, por sua vez, também é linguagem e não há linguagem sem compreensão. A linguagem é o que possibilita a existência de uma unidade entre ser humano e mundo, entre pensamento e coisa, entre sujeito e objeto ${ }^{37}$. Ela é aquilo que possuímos em comum com o mundo, com a tradição, com as coisas, com os

34 Cf. HEGEL, G. W. F. Phänomenologie des Geistes. Stuttgart: Reclam, 2003.

35 GADAMER, H-G. Wahrheit und Methode, p. 383.

36 GADAMER, H-G. "Mensch und Sprache" [1966]. In: Wahrheit und Methode: Ergänzungen; Register, p.150.

37 A tese de Gadamer sobre a linguagem é um dos exemplos da superação do dualismo externo entre ser humano e mundo. 
outros. Sem ela não podem haver sentidos a serem compreendidos. Não há quase nada escrito em Verdade e método que fale explicitamente sobre a identificação entre ser e linguagem, embora nessa obra muitos dos argumentos de Gadamer apontem para isso.

A consequência óbvia de não se ter desenvolvido claramente essa questão, apesar de ela possuir uma relevância manifesta para a compreensão de Verdade $e$ método, é o surgimento de incontáveis interpretações equivocadas de suas teses. Em primeiro lugar, há diversas apropriações indevidas de trechos dessa obra, que dizem respeito, por exemplo, a obras de arte, ao estudo de línguas, ao direito, à religião, etc., que ignoram que a hermenêutica de Gadamer seja ela mesma um modo de se fazer Filosofia e não um método para certas ciências. Em segundo lugar, aceitando-se isto, há a dificuldade de determinar a relação dessa hermenêutica com a filosofia do passado e, principalmente, com a metafísica. Essa tarefa Gianni Vattimo e Richard Rorty tomaram em certo sentido para si.

Vattimo é um dos intérpretes a concordar que existe na expressão "Sein, das verstanden werden kann, ist Sprache" uma defesa de que linguagem é ser. Ele principia sua argumentação ao se deter em um aspecto quase marginal naquela frase de Gadamer, como uma vírgula. Em alemão, tal afirmação possui duas vírgulas, mas, segundo Vattimo, se na sua tradução para as línguas latinas essa acentuação for mantida, pode-se entender que Gadamer identificou o campo dos objetos estáticos com o campo da linguagem. Por outro lado, se as duas vírgulas forem retiradas, percebe-se que com aquela tese ele quis dizer que o ser é linguagem e pode ser compreendido ${ }^{38}$.

Seguindo essa ideia, a tradução de Vattimo consta no francês sem as vírgulas. Discordamos no que concerne à mudança significativa que o uso ou não da vírgula pode trazer nessa tradução, para o português ao menos, embora prefiramos traduzir sem as vírgulas por uma questão de melhor fluência na leitura da frase. Sem uma compreensão da teoria de Gadamer sobre a linguagem, com vírgula ou sem vírgula pode-se confundi-lo com um idealista empírico, isto é, como se ele identificasse o ser com a linguagem em sentido falado, com um dado ou com um instrumento, que possuem certas estruturas fixadas de modo permanente. Contudo, concordamos com as consequências daquela especulação de Vattimo com relação à vírgula. Uma delas é a seguinte:

seria possível extrair [daquela afirmação de Gadamer] a tese de que "há" um ser que não pode "ser compreendido"? Quer dizer, que "há" ser "antes" e "fora da" compreensão? (...) Se há um ser fora ou antes de chegar à linguagem, será necessário pensá-lo como uma presença “objetiva" ainda não "compreendida" no horizonte da

38 Cf. VATTIMO, G. Histoire d'une virgule. Gadamer et le sens de l'être. Revue Internationale de Philosophie, France, v.54, n.213, 2000, p.499. 
linguagem. Mas precisamente a linguagem é a (única) morada do ser ${ }^{39}$.

Mesmo que houvesse um ser fora da linguagem, não poderíamos compreendêlo, pois não compreendemos sem linguagem ou fora dela. Não temos uma confrontação com uma realidade ou objetividade exterior a partir da qual possamos descrever o mundo, a história, a linguagem. O que ocorre é o nosso pertencimento a uma tradição, a partir da qual podemos afirmar algo que faça sentido. Rorty também concorda que, com aquela sentença fundamental, Gadamer se afaste de posições empírico-analíticas ou metafísicas em torno da linguagem, apesar de não ser assumidamente contra nenhuma delas. Contudo, sua hermenêutica também seria uma forma atualizada de algumas das verdades do idealismo.

A tese principal do idealismo, por exemplo, que diz que a verdade se dá por meio da coerência, de uma "descrição identificadora", e não de uma coincidência com a natureza interior do objeto, corrobora, segundo Rorty, essa tese de Gadamer de que há uma linguagem comum. Com esta, ele não estava em busca da natureza intrínseca do ser, mas queria nos ensinar a redescobrir o processo que Rorty chama de "aumento da nossa compreensão": quanto mais interpretações temos à disposição e quanto melhor elas estão integradas umas com as outras, melhor compreendemos a coisa expressa nessas “descrições" 40 . Em termos gadamerianos, quanto mais estamos abertos a novas experiências e mais nos pomos à disposição de exercícios ao modo do diálogo, temos melhores condições de compreender de um modo diferente, "em um todo mais amplo e com critérios mais justos" ${ }^{41}$.

Para Vattimo, defender que a nossa compreensão depende de uma historicidade, ou seja, de certos acordos na história, para que ela aconteça, significa apenas assumirmos a responsabilidade de declarar a nossa finitude e, assim, não nos julgarmos detentores da linguagem ${ }^{42}$. No fundo, o esforço de Gadamer de encontrar um sentido comum do que seja compreender, o conduz à própria “superação" da postura idealista que almeja um conhecimento acabado da realidade. Contudo, identificar a posição da filosofia hermenêutica ante o idealismo traz os seguintes questionamentos: já que possuímos uma pretensão de verdade, uma vez que sem ela o interesse em dialogar nem faria sentido, como determinar seus critérios? Como defender que haja algo em comum entre as relações por mim estabelecidas e a tradição? Ou ainda, como saber se do acordo no diálogo surgem concepções corretas e/ou aplicáveis? Há uma verdade hermenêutica?

\footnotetext{
39 Idem, p.502.

40 RORTY, R. “"El ser que puede ser compreendido es lenguage'”. In: HABERMAS, J.; RORTY, R.; VATTIMO, G. (et.al.). "El ser que puede ser compreendido es lenguage". Homenaje a Hans-Georg Gadamer. Madrid: Editora Sintesis, 2003, pp.45-48.

41 GADAMER, H-G. Wahrheit und Methode, p. 310.

42 VATTIMO, G. “Histoire d'une virgule. Gadamer et le sens de l'être”, p.513.
} 
Respondendo a possíveis críticas, Gadamer declarou que falar de "linguagem comum" significa, não afirmar simplesmente quais objetos do mundo as palavras designam (função indicativa da forma das coisas) ${ }^{43}$, mas mostrar para quais significações possíveis elas apontam num dado contexto (conteúdo da coisa). Isso é o que nós entendemos por “conceito" 44 e o esforço do conceito, de elaborar orientações que nos faça estar em uma situação de familiaridade com o mundo, mesmo quando este sofre constantes mudanças, é a tarefa da Filosofia. Desse modo, interpretar a tradição seria converter os conceitos do passado em algo atual, o que só é possível se já possuímos certa compreensão desses conceitos e se essa atualização passará a ser válida para mais de um indivíduo (caráter intersubjetivo da linguagem), de tal modo que sejamos impelidos a testar nossos conceitos diante dos outros e, consequentemente, autoavaliá-los.

Como nos afirma Jean Grondin: "a compreensão nunca pode tornar-se um problema teórico puro, uma vez que permanece determinada pela autocompreensão do ser humano" ${ }^{45}$. Ela depende, segundo Gadamer, dos efeitos da história e da linguagem sobre nós. O princípio da "história continuamente influente" mostra justamente que a compreensão não ocorre em um nível puramente ideal, mas ela atua, sofrendo e gerando uma série de transformações. Vattimo expressou muito bem esse ganho da hermenêutica ao assinalar que "a ontologia hermenêutica de Gadamer tem seu núcleo na identificação entre realidade [Wirklichkeit] e história continuamente influente" 46 .

De um modo geral, sabemos que o sentido dos conceitos se modifica de certo modo ao longo da história e que, portanto, a interpretação que fazemos dos sentidos das coisas sempre se dá na forma de uma aproximação. Os sentidos não são aleatórios, já que são partilhados, mas não há realmente garantias de uma interpretação verdadeira, no sentido estrito de uma cópia. Por isso, "não pode haver uma interpretação correta 'em si'. A vida histórica da tradição consiste na sua dependência a apropriações e interpretações sempre novas" ${ }^{47}$. Para que haja uma compreensão autêntica, a interpretação conterá, em primeiro lugar, uma possível referência a outras interpretações, pois, embora os conceitos possuam uma mobilidade histórica, isto é, o seu sentido se modifique, essa modificação não ocorre de um modo que tal sentido se desvincule da coisa em questão. Portanto, aqui não

43 Cf. GADAMER, H-G. Wahrheit und Methode, pp.407-408.

44 "O conceito é o verdadeiro ser, assim como nós costumamos usar a palavra 'conceito'" (GADAMER, H-G. "Begriffsgeschichte als Philosophie" [1970]. In: Wahrheit und Methode: Ergänzungen; Register, p.77).

45 GRONDIN, J. Hermeneutische Wahrheit? Zum Wahrheitsbegriff Hans-Georg Gadamers. Weinheim: Beltz Athenäum Verlag, 1994, p.174.

46 VATTIMO, G. “Comprender el mundo - transformar el mundo". In: RORTY, R.; VATTIMO, G. (et. al.). "El ser que puede ser compreendido es lenguage", p.67.

47 GADAMER, H-G. Wahrheit und Methode, p.401. 
há relativismo.

Ainda em defesa de Gadamer, Rorty afirma que quem pergunta pelos critérios daquela tese imagina que possamos transformar a linguagem, no futuro, em um instrumento. Esse é o tipo de gente que crê que pode manipular a história e encontrar algo por trás dela, e que nós temos condições de construir um sistema ordenado para tudo que possa aparecer no futuro, pondo na frente de tudo essa nossa suposta forma de pensamento privilegiada ${ }^{48}$. Entretanto, isso destrói o próprio caráter especulativo da linguagem. Toda compreensão autêntica da linguagem desperta e converte algo em uma nova imediaticidade, mostrando que embora signo e símbolo não sejam por si mesmos portadores de sentido, eles fazem parte de uma trama de efeitos recíprocos juntamente com o sentido e a compreensão. É por isso que por vezes a coisa parece se converter em conceito, mas o conceito, na verdade, já é a própria coisa; aquele se modifica quando essa também se modifica.

Não compreendemos, portanto, primeiro o conceito e depois a coisa, ou o contrário, mas o que compreendemos com o conceito é a coisa e o que compreendemos com a coisa é o conceito dela. Por essa razão, o que permanece na compreensão é sempre a própria coisa em questão e, portanto, não há uma coisa em si a ser buscada. A interpretação, por ser a cada vez distinta, não pretende pôr-se no lugar da obra interpretada, ela é sempre, todavia, um acidente que decorre da motivação de uma pergunta hermenêutica, a qual já faz parte da própria tradição de sentido. Além disso, como surge de motivações, de expectativas de sentido, a interpretação está obrigada a colocar suas ênfases, a não ser cópia e, como tal, não ser igual a outras interpretações.

Mesmo a articulação de palavras e coisas se manifesta de modos distintos em diversas línguas. Ela representa em todos os momentos uma primeira formação de conceitos natural, pragmática, guiada por suas necessidades e interesses, muito distante do sistema de conceituação científico ${ }^{49}$. Este forma os conceitos após identificar, com o seu esquema lógico de indução e abstração, aquilo que é comum a coisas diversas e supõe que isso seja o conteúdo objetivo das coisas. Deveria suscitar ao menos uma estranheza, que um produto da inteligência humana possa medir a vida humana em toda sua amplitude. Mas é isso que está por trás do ideal científico moderno: a tese metafísica de que a ciência pode apreender a essência das coisas.

A hermenêutica de Gadamer certamente não pode concordar com isso, embora não negue de modo algum a importância de se fazer ciência. Ela também não está de acordo com a tradição metafísica e suas entidades metafísicas, como,

48 Cf. RORTY, R. “'El ser que puede ser compreendido es lenguage'”, p.54.

49 "Antes de todo pensamento crítico-filosófico-interventivo, o mundo já é sempre apresentado para nós em uma forma de linguagem. Ao aprender uma língua, o mundo se articula para nós a partir da assimilação de nossa língua materna. Isso é mais uma primeira abertura do que um engano" (GADAMER, H-G. “Begriffsgeschichte als Philosophie”, p.79). 
por exemplo, a substância. De um modo geral, as principais filosofias, depois da elaboração heideggeriana do conceito de finitude, preferiram o termo "ontologia" a "metafísica". E uma ontologia hermenêutica tem como preocupação central a compreensão da mobilidade do sentido, da formação de conceitos, ao invés da determinação da essência das coisas. A linguagem como acontecimento do ser, ou o próprio ser, institui-se justamente "em virtude da margem de variação necessária e legítima na qual o espírito humano pode articular a ordenação essencial das coisas"

O que faz com que os conceitos possuam uma mobilidade histórica são justamente os diversos acordos entre palavra e coisa, que podem produzir um número infinito de novas relações e contextos. Para Rorty, "enquanto o metafísico perguntará se existem realmente as relações expressas no novo vocabulário, o gadameriano só perguntará se essas relações podem relacionar-se com o vocabulário anterior de um modo que sirva para algo" ${ }^{11}$, que continue valendo. Se, por um lado, a linguagem oferece "diversas possibilidades de expressar uma mesma coisa"52, por outro, o que se conserva na tradição são conjunturas (estados de coisas; situações), as quais podem permanecer abertas a outras conjunturas possíveis, ou seja, a toda espécie de ampliação, desde que ligada à sua própria configuração inicial.

A verdade que a ciência positivista nos apresenta, por exemplo, também é relativa a uma determinada experiência, não sendo correta a sua pretensão de neutralidade, nem de ser válida para tudo. Ao se basear no vocabulário da metafísica, buscando o "em si” das coisas, isto é, tentando apreender aquilo que é permanente frente a tantas mudanças, a ciência formulou algumas descrições novas para o mundo físico e conseguiu relacionar melhor algumas teorias antigas às novas, criando novos predicados para os seus objetos ${ }^{53}$. Não obstante, "no acontecimento da linguagem não encontra lugar somente aquilo que persiste, mas também e justamente a mudança das coisas". Gadamer ainda complementou dizendo que "a objetividade que a ciência conhece, e pela qual ela própria recebe sua objetividade, pertence às relatividades que abrangem a relação da linguagem com o mundo" 54 .

Podemos até falar de uma "objetividade" [Sachlichkeit] da linguagem, mas não no mesmo sentido que aquele da objetividade [Objektivität] exigida pela ciência positivista. A “objetividade" que a nossa experiência da linguagem nos proporciona, de conhecer as coisas, não elimina a parcialidade de nossas considerações sobre o mundo, como as ciências da natureza supõem ser possível. Ao contrário, a tentativa de compreensão da linguagem é a possibilidade não só de conhecimento do mundo,

50 GADAMER, H-G. Wahrheit und Methode, p.440.

51 RORTY, R. "'El ser que puede ser compreendido es lenguage”", p.54.

52 GADAMER, H-G. Wahrheit und Methode, p.448.

53 Cf. RORTY, R. “'El ser que puede ser compreendido es lenguage”, p.47.

54 GADAMER, H-G. Wahrheit und Methode, pp.453-454. 
mas também de transformação da tradição e de nós mesmos. Mas como sabemos disso, se o fundamento mais determinante do fenômeno hermenêutico é "precisamente a finitude de nossa experiência histórica" ${ }^{55}$ ?

Como afirmou Vattimo, não falar que linguagem é ser talvez tenha comprometido o pensamento de Gadamer ${ }^{56}$, no sentido de que, com a sua tese sobre a linguagem, ele pode dar a entender, como sugere Karl-Otto Apel, que aí haja uma tese metafísica segundo a qual a estrutura de uma "fusão de horizontes", própria da linguagem, "pode ser constatada em todo e qualquer caso do compreender" 57 , ou que, como diz Jürgen Habermas, ele seja permissivo com relação a certos acordos que foram feitos ou que continuam sendo feitos, mas que representam uma ameaça para o conhecimento ${ }^{58}$.

No tocante a esta crítica de Habermas, pensamos que não é pelo fato de Gadamer afirmar que existam experiências inautênticas que ele concorde com elas. Ele também não afirma em nenhum momento que os acordos que já se dão há algum tempo continuem existindo e sendo válidos somente pelo tempo de conservação. A abertura para que haja a "superação" de preconceitos negativos é recorrente no pensamento de Gadamer. Nós diríamos que o problema surgido aqui se deu porque ele não desenvolveu suficientemente um discurso sobre a proximidade ou a tensão entre a compreensão autêntica e a possibilidade de sua aplicação em uma situação real. Isso ele realmente não fez, mas a todo o momento ele foi defensor de acordos que tendam a evitar o maior número possível de violência contra o saber.

Com relação à primeira crítica, podemos afirmar, parcialmente em acordo com Apel, que a ontologia de Gadamer tem sem dúvida uma pretensão de universalidade. Embora este autor não fale de uma identificação entre ser e linguagem, ele nos sugere que haja uma anterioridade da linguagem em relação à compreensão. No entanto, isso deve excluir a ideia de uma "estruturação essencial do ente" e, assim, da necessidade de conhecimento de uma essência das coisas. Não há aqui uma ambiguidade. A "fusão de horizontes" vale para toda forma de compreensão no seguinte sentido: ampliamos, de algum modo, os nossos conhecimentos, na medida em que mantemos o nosso interesse pela verdade e, assim, tanto investigamos a tradição como a questionamos. Contudo, isso não indica que aqui vá explicitar-se o modo como esses horizontes se deslocam, nem significa que em todo o caso há compreensão correta.

Segundo Rorty, Gadamer segue de certo modo o nominalismo, na medida em

\section{Idem, p.461.}

56 Cf. VATTIMO, G. "Histoire d'une virgule. Gadamer et le sens de l'être”, p.502.

57 APEL, K-O. Transformação da Filosofia I: Filosofia Analítica, Semiótica, Hermenêutica. Tradução de Paulo Astor Soethe. 2a ed. São Paulo: Edições Loyola, 2005, p. 33.

58 Cf. HABERMAS, J. Dialética e hermenêutica. Tradução de Álvaro Valls. Porto Alegre: L\&PM, 1987, pp.16-18. 
que defende que todas as entidades por nós compreendidas são da ordem daquilo que pode ser dito, ou melhor, expresso de algum modo em uma cultura. Além disso, este filósofo não estabelece uma ordem hierárquica ou uma classificação ontológica das coisas $^{59}$. Aqui nominalismo e idealismo parecem ser dois nomes de uma mesma posição filosófica, a qual, distanciando-se das formas tradicionais daquelas teorias e incorporando parte de suas contribuições, pretende se afastar dos resíduos metafísicos da tradição. 0 fato de a experiência hermenêutica ser uma experiência da finitude significa que, embora nela também se busque a formação de um conceito em coerência com a história (idealismo), esse conceito é passível de compreensão e não conhecemos outras formas, hierarquicamente melhores e exteriores à linguagem, de apreendê-lo (nominalismo).

Embora a busca por uma compreensão autêntica pareça representar a "superação" [Überwindung] de concepções parciais em direção do conceito adequado, não há aqui a tentativa de estabelecer uma nova forma de poder, isto é, de criar o melhor sistema, que descreva as coisas de maneira mais correta. Quando Gadamer afirmou que "a própria demonstração filosófica faz parte da coisa"60, ele queria dizer que naquela reside uma possibilidade de "superação" de preconceitos negativos, no sentido de um voltar-se para novos propósitos [Verwindung]. Em outros termos, a descrição da coisa faz parte de uma “linguagem comum”, que mantém em aberto o potencial de revisão das próprias descrições.

Gadamer fundou uma nova forma de articular a Filosofia a partir da reflexão sobre a linguagem que the subjaz. Certamente o que aqui se desdobra é uma ontologia. Entretanto uma ontologia revirada linguisticamente, que não busca por um fundamento exterior ou unilateral da relação histórica do ser humano com o mundo, mas que vê na própria linguagem em que transita a esfera onde o mundo se diz e a condição de sua possibilidade.

Quando Gadamer disse que "Ser que pode ser compreendido é linguagem" ele admitiu que a sua hermenêutica é uma filosofia do ser, não do ser metafísico, mas do ser da linguagem, da história, da tradição. Desse modo, a verdade que Gadamer quis destacar, com a sua obra Verdade e método, foi aquela ligada à experiência humanístico-histórica que fazemos a cada instante que somos no mundo, e que não pode ser ensinada e nem guiada por um padrão, senão vivida. Em outros termos, ela não é uma verdade matemática, mas aquela que é procurada quando nos deparamos com algo estranho, que contradiz as nossas expectativas habituais. Crescem as promessas de que as novas ciências empíricas possam dissipar tal estranheza, controlando todos os âmbitos da vida. Mas será que estas ciências estão mesmo em condições de satisfazer essas exigências?

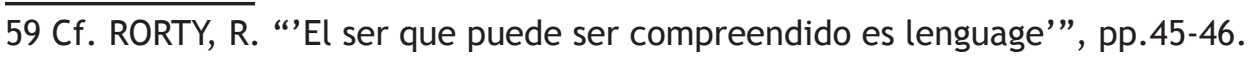

60 GADAMER, H-G. Wahrheit und Methode, p.472. 
Pode a medicina, e outras ciências da saúde, com o estímulo à prevenção e a luta contra enfermidades, eliminar a estranheza com relação ao tempo futuro e à morte? Pode a psicanálise, com a criação de métodos de análise na direção de um equilíbrio entre os impulsos instintivos e os motivos conscientes, acabar com a nossa estranheza diante daquilo que somos ou nos tornamos? Podem as ciências econômicas, com o estudo dos fenômenos relativos aos bens materiais e as suas fórmulas para o bem-estar geral, dissipar a estranheza frente ao tema da liberdade? Pode a linguística, ao tentar estabelecer precisamente o uso de cada idioma ${ }^{61}$, eliminar a estranheza do outro que quer ser compreendido? Caso afirmativo, não haveria mais o que parecem ser invenções propriamente humanas, como planejamento errado, suicídio, guerras, desentendimentos, nem muito menos se viveria mais as tensões entre o sentido para o correto e o incorreto, em ser outro de si mesmo, entre domínio e subjugação, entre público e privado62.

Isso não quer dizer que a ciência não cumpra o seu papel de nos proporcionar em certos termos longevidade, reintegração à vida social, acordos políticos, estruturação da vida pública, acesso à informação, etc. Contudo, isso significa que ela possui limites ante os problemas da vida que mais nos causam medo e são decisivos, inclusive para fazer com que os resultados das ciências se convertam para nós em um bem. É por isso que, para Gadamer, também a ciência precisa desenvolver uma consciência hermenêutica, isto é, uma consciência filosófica. Mais ainda, ele acreditava que a ciência integrada ao saber do ser humano sobre si mesmo poderia conduzir-nos a uma nova autocompreensão da humanidade ${ }^{63}$. Em razão disso, Gadamer nunca acreditou em um fim da Filosofia. Pelo contrário, ele insistiu na necessidade da reabilitação de sua tradição.

Isso remonta ao começo da Filosofia, o qual, segundo Platão, surgiu com o

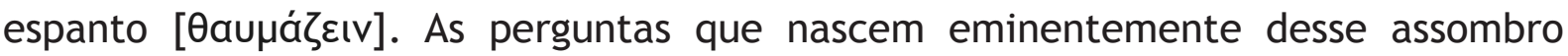
caracterizam-se como questões filosóficas. Em outras palavras, a Filosofia serve justamente para compreender o estranho. Já a hermenêutica filosófica assume, ainda mais radicalmente, a tarefa de mostrar como esse modo de compreender ainda precede os demais. Ele é a própria compreensão no sentido mais autêntico, na medida em que se caracteriza como a possibilidade mais genuína de abertura para a escuta do outro. Segundo Gadamer, quem considera que com a hermenêutica se possa dizer algo filosoficamente relevante precisa saber que alguém somente estará

61 Cf. GADAMER, H-G. “Über die Naturanlage des Menschen zur Philosophie” [1971]. In: Vernunft im Zeitalter der Wissenschaft: Aufsätze. 3. ed. Frankfurt am Main: Suhrkamp Verlag, 1991, pp.117121.

62 Cf. GADAMER, H-G. "Historik und Sprache" [1987]. In: Hermeneutik im Rückblick. Gesammelte Werke, Bd. 10. Tübingen: Mohr Siebeck, 1999, p.328.

63 Cf. Idem. "Über die Naturanlage des Menschen zur Philosophie”, p.123. 
Sobre a tese "ser que pode ser compreendido é linguagem"...

em condições de compreender algo se estiver disposto a escutar ${ }^{64}$.

\section{Conclusão}

Com isso, vê-se a ligação da tese hermenêutica de que "ser é linguagem" com aquela outra de que a compreensão possui uma dimensão prática. Só compreendemos a linguagem do outro no diálogo. Além disso, na medida em que nos distanciamos de nossas próprias convicções para ouvir o que o outro tem a nos dizer, retomamos a chance de compreender de um modo novo, com critérios novos. Aí temos o acesso a outra linguagem, que nos pode ajudar a conhecer melhor a nós mesmos, a formar o sentido moral para a solidariedade, a adquirir uma visão de mundo mais livre, a ter esperança e, assim, a lidar melhor com a angústia da morte, as desventuras da vida, as injustiças e os sofrimentos.

Por um lado, o milagre da distância, que conquistamos com a linguagem, pode proporcionar isso, por outro, ele pressupõe uma perigosa incerteza. É sobre esta que a hermenêutica de Gadamer se debruça de uma maneira especial. Ao mesmo tempo em que abandonamos nossas certezas, para talvez adquirirmos por meio de outra linguagem uma compreensão melhor das coisas, não há a promessa de nenhum resultado imediato, mas sim de algo futuro. Buscar compreender a cada de vez de modo correto, testando e deixando o outro pôr à prova aquilo que se pressupõe saber no diálogo e, assim, projetando as metas para longe, foi a grande iniciativa humana criada para estabelecer os nossos limites, a ela chamamos de Filosofia. Mesmo quando há mal-entendido, ao invés de concordância, existe sempre a chance de ordenarmos tudo novamente e inserirmos as coisa em algo comum.

Segundo pensamos, para Gadamer, a compreensão está completamente limitada pelo diálogo com o outro e, como tal, ela possui uma dimensão prática em defesa de uma comunidade linguística. Isso de modo algum pode ser negligenciado se queremos fazer jus à sua filosofia hermenêutica. Portanto, a tese "ser é linguagem" esconde algo, isto é, que o ser só pode ser compreendido ao modo do diálogo. Isso no fundo é uma reabilitação da sabedoria prática grega e da ideia de phrónesis

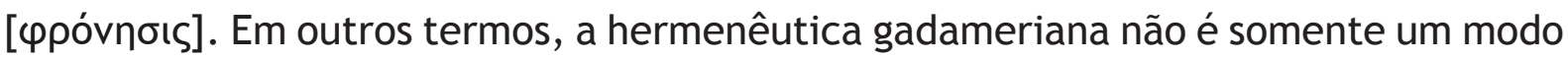
de se fazer Filosofia, mas uma atualização da filosofia prática grega.

\section{Referências}

APEL, K-O. Transformação da Filosofia I: Filosofia Analítica, Semiótica, Hermenêutica.

Tradução de Paulo Astor Soethe. 2a ed. São Paulo: Edições Loyola, 2005.

ARISTÓTELES. “Periérmeneias”. In: Organon. Tradução de Pinharanda Gomes. Lisboa:

Guimarães Editores, 1985, pp.123-128.

64 Cf. Idem. "Historik und Sprache", p.324. 
DILTHEY, W. “Origens da hermenêutica”. In: Textos de hermenêutica. Tradução de Alberto Reis. Lisboa: Rés, 1984, p.167.

GADAMER, H-G. Die Lektion des Jahrhunderts: ein Interview von Riccardo Dottori. Münster: Lit, 2002.

. Hermeneutik im Rückblick. Gesammelte Werke, Bd. 10. Tübingen: Mohr Siebeck, 1999, p.328.

O problema da consciência histórica. Tradução de César Duque Estrada. Rio de Janeiro: Editora Getúlio Vargas, 1998.

. Vernunft im Zeitalter der Wissenschaft: Aufsätze. 3. ed. Frankfurt am Main: Suhrkamp Verlag, 1991.

Wahrheit und Methode: Ergänzungen; Register. 2. ed. Gesammelte Werke, Bd. 2. Tübingen: Mohr Siebeck, 1993.

. Wahrheit und Methode: Grundzüge einer philosophischen Hermeneutik.

6. ed. Gesammelte Werke, Bd. 1. Tübingen: Mohr Siebeck, 1990.

GRONDIN, J. Hermeneutische Wahrheit? Zum Wahrheitsbegriff Hans-Georg Gadamers. Weinheim: Beltz Athenäum Verlag, 1994.

HABERMAS, J. Dialética e hermenêutica. Tradução de Álvaro Valls. Porto Alegre: L\&PM, 1987.

RORTY, R.; VATTIMO, G. (et.al.). "El ser que puede ser compreendido es lenguage”. Homenaje a Hans-Georg Gadamer. Madrid: Editora Sintesis, 2003. HEGEL, G. W. F. Phänomenologie des Geistes. Stuttgart: Reclam, 2003.

HEIDEGGER, M. Conferências e escritos filosóficos. 2. ed. Tradução de Ernildo Stein. São Paulo: Abril Cultural, 1983

- Ensaios e conferências. 3.ed. Tradução de Marcia Sá Cavalcante

Schuback. Petrópolis: Vozes, 2006. Sein und Zeit. Tübingen: Max Niemeyer Verlag, 1967.

HUSSERL, E. Lições para uma fenomenologia da consciência interna do tempo. Tradução de Pedro M. S. Alves. Lisboa: Imprensa Nacional, 1994.

SCHLEIERMACHER, F. D. E. Hermenêutica e crítica. Tradução de Aloísio Ruedell. Rev. Paulo R. Schneider. Ijuí: Editora Unijuí, 2005.

Hermenêutica: arte e técnica da interpretação. 5.ed. Tradução de Celso Reni Braida. Bragança Paulista: Editora Universitária São Francisco, 2006. VATTIMO, G. Histoire d'une virgule. Gadamer et le sens de l'être. Revue Internationale de Philosophie, France, v. 54, n. 213, 2000. 